\title{
ANTI-BLACK RACISM AND COMMUNITY VIOLENCE: AN AUTOETHNOGRAPHY OF THE EXPERIENCES OF A BLACK MALE SOCIAL WORKER IN COMMUNITY SETTINGS
}

\author{
by \\ Olu Quamina, BSW, Ryerson University, 2016 \\ An MRP \\ presented to Ryerson University \\ in partial fulfillment of the \\ requirements for the degree of \\ Master of Social Work \\ in the program of \\ Social Work
}

Toronto, Ontario, Canada, 2020

(C) Olu Quamina, 2020 


\begin{abstract}
AUTHOR'S DECLARATION
I hereby declare that I am the sole author of this MRP. This is a true copy of the MRP, including any required final revisions.
\end{abstract}

I authorize Ryerson University to lend this MRP to other institutions or individuals for the purpose of scholarly research

I further authorize Ryerson University to reproduce this MRP by photocopying or by other means, in total or in part, at the request of other institutions or individuals for the purpose of scholarly research.

I understand that my MRP may be made electronically available to the public. 


\begin{abstract}
Anti-Black Racism and Community Violence: An Autoethnography of the Experiences of a Black Male Social Worker in Community Settings

Master of Social Work, 2020

Olu Quamina

Social Work, Ryerson University
\end{abstract}

This research represents a highly personalized account of my experience as a black male frontline worker supporting black families impacted by community violence. Using myself as the subject this paper explores complexities of navigating community violence in relation to structural violence, anti-black racism mental health impacts. Through utilizing autoethnography as a methodology this paper examines two transformative events that provides an insider's vantage point into the challenges I have faced as a black man within my practice. Through sharing my experience, I hope to raise awareness about the impacts on mental health on frontline workers that support communities that experience trauma. 


\section{ACKNOWLEDGEMENTS}

I would like to thank my supervisor Gordon Pon for the support, encouragement and patience, throughout this process.

I would like to thank the entire faculty of the Master of Social Work program at Ryerson University. I would specifically like to thank my professors Idil Abdillahi, May Friedman, Notisha Mossaquoi, Purnima George and Karen Arthurton for sharing knowledge, wisdom and understanding about social work practice.

I would also like to give a special shout out to each and every person that dedicates their lives to supporting our most vulnerable youth in community settings. 


\section{DEDICATION}

To my wife, Karima whose constant encouragement and unwavering support carried me throughout this challenging journey. THANK YOU!

To my children, for always reminding that I need to complete my paper!

To my parents, your confidence and belief in my abilities has never faltered. 


\section{TABLE OF CONTENTS}

Introduction

Page \#1

Literature Review

Page \#4

Theoretical Framework

Page \#18

Methodology

Page \#22

Transformative Events \&Analysis

Page \#25

Implications

Page \#41

Conclusion

Page \#48

Reference List

Page \#50 


\section{INTRODUCTION}

This paper is an account of my experiences as a Black male social service worker working with families in underserved neighbourhoods. This paper aims to explore the research question: How does anti-Black racism impact Black social service workers who support Black youth in underserved communities? To conduct this research, I will utilize ethnographic methodologies and critical race frameworks to explore how a Black male social service worker engages with 1) the complexity of the tenets of the anti-Black racism that underwrite young people's lives and, 2) how anti-Black racism can impact a Black social service worker who serves Black youth populations. I will critically examine the notion of violence and explore how it relates to anti-Black racism and the mental health and well-being of Black social service workers.

This qualitative research autoethnography will provide a unique view of how exposure to community violence can impact overall health and well-being of frontline social workers. This paper will explore how my social location as a Black man intersects with my professional practice. It will also speak to the mental health impacts of navigating the violence of anti-Black racism at the structural, organizational and personal levels.

To provide some background, over the last twenty years, I have dedicated my life to engaging Black youth from racialized and marginalized communities across the City of Toronto. In my practice engaging racialized males and Black families, I have had to support those who had experienced everything from racial profiling to community gun violence. These incidents greatly impacted the young people who were involved, as well as the families and community members who had been touched by the ripple effects of trauma. One of the more challenging aspects of my work has been having to cope with the mental health impacts of supporting those 
who experienced inequitable treatment from police, as well as the victims of community gun violence, and at times, even those who had initiated the violence. According to Abt (2017) violence comes in many forms and "community violence" should always be contextualized alongside other forms of violence. The purpose of this research is to explore my experiences of the impacts of exposure to community violence in relation to how structural/ institutional workplace violence interplays with anti-Black racism. It impacts who I am, how I experience and interpret violence within my community context and broader environment.

As a Black man, my social location is the same as many of the victims on Toronto's homicide list and unfortunately, many of the perpetrators as well. I feel particularly connected to the work because when I look back and reflect on my adolescent years, I realize how easily I could have been on either of the aforementioned lists. As a Black man living in what dominant culture would identify as Toronto, I am very much subject to discourses of community violence in relation to anti-Black racism and ultimately subject to the mental health impacts linked to exposure to community violence. The purpose of this autoethnography is to explore my experiences as a Black man and social worker practicing in underserved communities that experience community violence. As exposure to community violence continues to grow, it is imperative that we begin to understand the mental health impacts on frontline social service professionals. The aim of this research is to amplify the voice of frontline social workers and identify gaps in personal and workplace supports as a result of serving populations that experience trauma.

\section{Intention}


As the author, I understand my obligation to a) provide accurate accounts of my experiences b) to protect the identity of the individuals mentioned in the personal accounts and c) to amplify the voice of community-based social workers who have similar experiences. Autoethnography will be utilized by way of a narrative approach to critically examine key transformative events that have shaped my experiences as a Black male social worker in relation to violence, mental health and racism.

This paper will use anti-Black racism (A-BR) and critical race as the theoretical frameworks that inform the analysis of the qualitative research autoethnographic accounts. By analyzing the accounts through anti-Black racism and critical race theoretical frameworks, my intention is to share how anti-Black racism plays an implicit role in adding to the variables that impact the mental health, particularly the vicarious trauma, of Black social service workers serving Black youth populations. These accounts highlight the various manifestations of community violence through marginalization of Black peoples in the various roles they take up in their communities. By way of utilizing anti-Black racism as a theoretical framework this research study will introduce a much-needed critical race perspective to existing research paradigms in the areas of exposure to community violence and the impacts on mental health on frontline social service professionals.

I believe that anti-Black racism is strategically positioned as the focal point to address issues of oppression, marginalization and ultimately community violence in a very deliberate manner. Thus, I assert that anti-Black racism and critical race as theoretical frameworks, in conjunction with an autoethnographic study, will provide a unique understanding of my experiences.

\section{LITERATURE REVIEW}


Considerable empirical evidence shows that working with traumatized populations poses hazards for the practitioner (Cunningham, 2003). This literature review will summarize what research has been done in these areas and uncover the gaps where supports for workers who serve populations that experience trauma are concerned. In the process, this literature review explores epistemological paradigms, theoretical frameworks and identifies how the knowledge was constructed. It will also critique both the strength and limitations of the studies and explore how knowledge was produced by critically examining the methodologies utilized in the respective studies. Exposure to community violence, anti-black racism, mental health, vicarious trauma and organizational supports for frontline workers who serve populations that experience trauma are the main themes that emerged from this literature review.

\section{Toronto Context re: Community Violence and Health}

In March of 2018, The Toronto Board of Health approved a motion that recognized exposure to community violence as a social determinant of health. The motion requested that the Medical Officer of Health sanction Public Health and Social Development and Financial Administration to explore the health impacts of exposure to community gun violence in Toronto, in addition to investigating the broader impacts at a community level, while identifying evidence-based violence intervention models to prevent incidents of community violence and negative mental health impacts in Toronto (Glover \& Mackooie, 2018). The National Child Traumatic Stress Network (2019) defines community violence as intentional acts of interpersonal violence often committed in public areas by individuals who are not intimately related to the victim (p. 1). This definition is most commonly used to describe violence amongst groups and gangs that involve the use of weapons and public shootings (City of Toronto, 2019). Given the 
amount of youth and families exposed to community violence, it is imperative to address the mental, physical and emotional impacts of this phenomenon (Margolin et al., 2010).

In October 2019, Toronto Board of Health released a report entitled Community Violence in Toronto: A Public Health Approach. The report provided evidence that individuals, families and communities exposed to community gun violence community violence indeed experience higher levels of anxiety, depression, vicarious trauma and PTSD (City of Toronto, 2019). Hansen-Nord et al. (2016) assert that violence prevention is a growing issue with serious implications on mental health and well-being of individuals who have been directly and indirectly exposed to trauma. Richardson (2001, p) defines vicarious traumatization as "the transformation of the therapists' or helpers' inner experience as a result of empathetic engagement with survivor clients and their trauma material". Vicarious traumatization "refers to the cumulative transformative effect on the helper working with the survivors of traumatic life events" (Richardson, 2001, p. 6). The report also suggested that that communities facing socioeconomic disadvantages, experienced disproportionate rates of community violence which particularly impacts the health of young men between 14-29 years old (City of Toronto, 2019). Additionally, Community Violence in Toronto: A Public Health Approach also examined homicide rates in Toronto between 2004-2014. The report found that Black and SomaliCanadian youth disproportionately experience community violence. The issue of community violence is particularly dire in the Somali Canadian community as homicide rate continues to increase while victims are getting younger and younger (Aden et al., 2018). The report further recognized various forms of community violence including individuals, groups, gangs involved in fights that involve the use of weapons in public and specifically named the use of firearm related crimes in Toronto. 
Given the evidence that suggests that communities facing socioeconomic disadvantages experience disproportionate levels of community violence, for Black and Somali-Canadian young men it is imperative to explore how anti-Black racism and various forms of structural and institutional racism directly perpetuates the phenomenon of community violence.

\section{Community Violence Exposure}

Assari and Caldwell's (2017) study investigated the relationship between neighbourhood safety and Major Disruptive Disorder (MDD) in Black youth. The frequency of exposure to community violence is higher in large urban cities and within impoverished enclaves. This accounts, in part, for the overrepresentation of racial minorities, especially African American males, among youth exposed to community violence (Zimmerman \& Messner, 2013). Assari and Caldwell's (2017) research was a cross-sectional study that used data from the National Survey of American Life-Adolescents (NSAL-A) 2003-2004, the largest and most updated mental health survey of Black youth in US history. Interviews were also made: $82 \%$ of interviews were face to face in the participants' homes, and the rest were conducted via telephone. The interviews lasted an average of 100 minutes and were conducted using computer assisted personal interviews (CAPI). The findings indicated that those who perceived their neighbourhoods as unsafe were at a higher risk for MDD, and that Black American males were more likely to perceive their neighbourhoods as unsafe. Assari and Caldwell's (2017) study pointed to the perception of unsafe neighbourhoods as a predictor of MDD, but it was interesting to note that Black American males were more likely to perceive their neighbourhoods as unsafe in comparison to Black Caribbean males and Black American and Black Caribbean females.

According to Benjet (2019), neighborhood-level violence may affect perceptions about safety, negativity toward the future, and hopelessness, all of which are symptoms of internalizing 
disorders. Further, neighborhood violence may impact these disorders through deterioration of social networks, isolation, collective efficacy, and perceptions of neighborhood disorder.

It would have been interesting to have these groups of Black youth define or describe what makes a neighbourhood unsafe, share their experiences with research communities and expand the academic conversations around Black youth and trauma. There are so many questions around the types of trauma that various groups of Black youth may be experiencing and whether or not those levels of trauma may differ from one culturally diverse Black neighbourhood to the next. This information could have been helpful to the organizations and frontline workers who engage with Black youth populations experiencing trauma. With this information, the frontline youth workers might be able to plan more interventions and/or create more neighbourhood support networks for themselves and their clients, while the organizations might anticipate some of the vicarious trauma (VT) that their youth workers might experience and potentially craft better policies that support them accordingly.

The Smith et al. (2019) study examined the prevalence of and differences in exposure to gun violence fatality across multiple demographic characteristics including race/ethnicity. The purpose of this study was to examine the associations between exposure to gun violence fatality and adverse mental health outcomes when controlling for significant demographic characteristics. This study utilized a quantitative research methodology and collected data using a survey from 1615 participants. The participants resided in Baltimore, New York, Philadelphia and Washington DC. The study found that Black, Latinx folk(s) from low income communities with lower education levels experienced disproportionately higher levels of exposure to gun violence fatality. As a result, respondents displayed higher levels of depression, psychological distress and suicidal ideation. The findings suggest that gun violence disproportionality affects 
racialized and minority communities; particularly Black and Latinx community members. Additionally, findings suggest that given the exposure to community gun violence (fatality), community level mental health interventions should be explored.

According to Benjet (2019), while extensive research has shown that direct exposure to violence is related to increased risk of both internalizing and externalizing mental disorders (Rosenthal, 2003), much less is known about the effects of neighborhood-level violence on the mental health of individuals who have not experienced such violence directly.

Bellas et al. (2019) in their Brazilian study explored the kinds of services provided by Community Health Workers (CHW) during the house calls they make in poorly developed areas. The aim of this study was to better understand the effects of urban violence on their working conditions. The sample consisted of $2000 \mathrm{CHWs}$ in Brazil and the data was collected via telephone interviews. Participants were asked to respond using a scale. The findings indicated that CHWs were unique in that they were exposed to urban violence almost daily and that the exposure increased their mental workload, stress and fatigue. The study also suggested that those factors could have interfered with their decision-making capacity, resulting in a potential compromise in their ability to have delivered optimal care. This study is really important because it illustrated how continued exposure to violence impacted the workers' ability to do their job effectively. Additionally, research suggests that the daily stress of violent neighborhoods can affect immune functioning and the methylation of genes implicated in internalizing disorders such as depression and PTSD (Galea et al., 2011). It would have been interesting to explore if the organizations had created supports for the workers to be able to continue to function in various contexts. This study solely looked at the CHWs' capacity to make decisions within their work, but what about when the worker went home? What impacts did that 
level of exposure to violence have on other kinds of decisions that were being made? What types of behavior did that exposure to violence illicit and/or how did it (if at all) carry over in other contexts? I believe a qualitative approach to these questions might uncover some ways in which these workers were coping (well or maladaptively) and how their workplaces could help support them.

\section{Mental Health and Frontline Work}

Several studies recognized secondary traumatic stress as an outcome for caring professions that support people who experience trauma. Devilly, Wright and Varker's (2009) study aimed to perform an assessment for secondary traumatic stress (STS), vicarious trauma (VT) and workplace burnout for Australian health professionals involved in clinical practice. This was a quantitative study that had 152 participants who completed a questionnaire online. The study found that the best predictors of therapist distress was the work-related stressors and not the exposure to client trauma. This study's findings are interesting in that with regard to stressors of therapists who have exposure to clients who experience trauma, the weight of the stress is not inherited from the clients, but rather from the workplace. This is so important to note because while there is some concern around STS and VT, this study suggests that it is almost more important to look at the stressors inherent in their workplace in relation to STS and VT. I think that a qualitative study would better explore the nuances in the therapists' experiences and could probably paint a more detailed picture of what those stressors actually are. It would be interesting to understand what these therapists' work-related stressors are, identify some of their symptoms and see if there might be similarities to other workers who serve populations that experience trauma. 
The Whiting-Blome and Safadi's (2016) study is a qualitative study that explored the perceptions of how Palestinian social service executive directors and social workers regarded the effects of working in a conflictual environment (East Jerusalem and West Bank). This was a multiple case design study. The data was collected across four Palestinian not-for-profits social service organizations through a) face-to-face interviews from executive directors, and b) through focus groups with social workers. The findings suggested that the external environment impacted the workers' performance, more specifically, the influence of a strong political climate and working with people in closed areas due to the Israeli separation wall. This study findings highlighted the impact that external forces (such as policy and governments) had on performance and creating a context in which workers effectively provided services for their clients. It would be interesting to have additional research that looks at how these policies not only impacted the workers' ability to provide effective supports for their clients, but how the workers themselves navigated their own mental health concerns given the context in which they found themselves, and what other supports (policies and so on) they thought would be helpful to address their concerns.

For example, Argentero and Setti's (2011) study aimed to investigate the incidence of symptoms of VT in a group of rescue workers; explore some of the main predictors of engagement and vicarious traumatization; and identify the individual and organizational factors that were able to improve the state of well-being of those working in the helping professions. This is a quantitative study that used the Mas-lach Burnout Inventory General Scale (MBI-GS) and the Secondary Traumatic Stress Scale (STSS). Argentero and Setti (2011) collected data from 782 participants. The participants were rescue workers who were involved in critical operations, and through their work, had repeatedly interacted with traumatic events and/or people 
who had experienced various levels of trauma. The study found that post-traumatic symptoms most frequently reported were those that seemed to interfere with participants' daily lives. The findings pointed to a partial overlap between the predictors of VT and engagement. The findings also suggested that a supportive working environment favoured engagement and reduced the probability of developing burnout. Argentero and Setti's (2011) study states that symptoms that were deemed "invasive" were the ones that were mostly reported, but what about the other workers who experienced trauma, and had not become aware or were in denial of how "invasive" their symptoms had actually become? How did those types of post-traumatic symptoms get taken up and how did it impact the way that rescue workers engaged with their work afterwards? If certain types of symptoms are not usually reported, and there are potentially impacts on how they continue to work, how do workers access supports? In this case, how is a "supportive working environment" defined? And who gets to define it? This study reinforces Devilly, Wright and Varker's (2009) research in that work environment contributes to how the worker continues (or not) their work after being exposed to VT and STS. Although these studies spoke to the importance of fostering a supportive workplace for workers who served populations that were exposed to trauma, the exploration of what organizations can do to support these workers needed to be further explored. This area needs to be explored further to better understand the gaps that need to be filled to help workers to a) continue their work of supporting others who have been traumatized, and b) address their own mental health concerns (STS, VT, burnout etc.) regarding their roles and responsibilities.

Hammonds' (2019) study builds on the subject of how workers perceive their own stress. Hammonds' (2019) study is a quantitative analysis that aimed to identify the differences in child social workers' levels of perceived stress based on levels of VT. The purpose of this non- 
experimental study was to examine four identified variables. The two dependent variables were VT and years of experience; and the two independent variables were levels of perceived stress and self-care. This study used four instruments: Demographic Questionnaire, Professional Quality of Life Scale (ProQOL), the Perceived Stress Scale, and the Wellness Assessment. The findings suggested that the social workers who experienced average levels of VT had significantly higher levels of perceived stress in comparison to those who had low levels of VT. Years of experience in their role did not seem to impact their perceived stress levels or VT. Conversely, those who experienced low levels of VT engaged in more self-care than those who experienced average levels of VT. Years of experience in their role also did not seem to impact levels of self-care. This study looks at relationships between years of experience, VT, self-care and perceived stress. Further inquiry is needed to understand why child social workers who have been exposed to lower levels of trauma engage in more self-care in comparison to those who have experienced average levels. A qualitative research methodology could have provided some insight regarding how workers define what self-care looks like. It might have also been able to explain what symptoms workers were trying to address through self-care. A qualitative research study might have also uncovered if there were any similarities between Cox, Johnson and Coyle 's (2015) study on coping strategies. For example, an open-ended interview could explore if selfcare included social coping strategies (Cox, Johnson, \& Coyle, 2015). It could also be an opportunity to explore if these self-care strategies might have been why workers reported certain types of post-traumatic symptoms over others (Argentero \& Setti, 2011).

Cox, Johnson and Coyle's (2015) study explored the relationships between coping styles, exposure to violence and work-related outcomes in Mexico. The study used quantitative research methods and used a brief version of the COPE scale (Carver, 1997). This scale is used 
widely to measure coping. It provides several behaviours that have been identified as strategies for coping with stressors. Data was collected from Mexican workers who were given statements and had to respond on a scale from 0-3. Findings suggested that social coping appeared to alleviate the relationship between exposure to violence in the community and intention to turnover. Regarding solitary coping, findings suggested that it could be beneficial when exposed to low levels of community violence, but not when exposed to high-level violence. Additionally, solitary coping did not predict job performance directly. With regard to maladaptive coping, findings suggested that it could lead to greater psychological strain after exposure to violence, irrespective of the level of exposure the worker had to community violence. This study linked categories of coping strategies to how it impacts the work; however, to really get a sense of what these workers identify as stressors, coping strategies, and how often coping strategies are being used, a qualitative study might be more suitable. It would be interesting to follow-up this research to see how the workplace engages (or not) with structures that facilitate coping strategies that workers feel are helpful (e.g., social coping strategies).

According to Hopwood et al. (2019), the phenomenon of compassion fatigue is a term that is often used interchangeably with secondary traumatic stress. The impacts are negative, and results are similar to those associated with post-traumatic stress disorder (PTSD). Hopwood et al. (2019) also explored the phenomenon of anticipatory traumatic reaction (ATR) amongst youth workers. These youth workers served vulnerable and traumatized youth populations by administering need assessments, referral reports, case management, residential care, home visits and interventions for vulnerable families. The study took place in Australia and aimed to examine conditions that stemmed from secondary exposure to trauma; more specifically, the relationship between ATR and fatigue compassion. Hopwood et al. (2019) suggest that ATR can 
be defined as a future focused form of distress that occurs as result of exposure to media and social discussions relating to events or threats. While the conditions that foster secondary traumatic stress, PTSD and ATR are similar, the study differentiates ATR as a future-focused form of distress. The researchers (Hopwood et al., 2019) used quantitative research methods and collected data from 48 youth workers using an online questionnaire. All participants worked for the same not-for-profit youth-centred organization. The study used Conservation of Resources (COR) theory (Hebfell \& Lilly, 1993) which provides a broad psychological framework that helps explain human reactions to both positive and negative events. It suggests that people rely on a stockpile of resources to cope with life's challenges and are thus motivated to collect and keep these resources to ensure continued wellbeing.

The study (Hopwood et al., 2019) found that the participants' levels of depression, anxiety and stress may play a significant role in linking secondary traumatic stress (attained through witnessing and listening to the trauma narratives of clients) to burnout. It also suggests that ATR exacerbate levels of distress, potentially putting youth workers at greater risk for burnout. The research calls for a clearer understanding of the factors that reduce both ATR and compassion fatigue. Hopwood and colleagues (2019) explain that given the importance of providing optimal care for clients, particularly vulnerable populations, the phenomenon of burnout is of growing concern.

Dombo and Whiting-Blome's study (2016) looked at the relationship between child welfare organizations and their workers' burnout. The research aimed to investigate the organizational responses to vicarious trauma in child welfare agencies. This was an exploratory research study designed to explore how the leadership of child welfare organizations conceptualized vicarious trauma and its connection to worker burnout and turnover; what child 
welfare organizations were doing to address VT among their workers; and how child welfare organizations responded to critical incidents. The study used purposive sampling and participants were administrators who were invited to participate in a 60-minute interview. Multiple emails and telephone calls were conducted to follow-up as necessary. The findings uncovered seven themes. The first theme addressed the strengths respondents shared about their organization, both in general and in relation to how it attempted to address VT among workers. The second theme related to the barriers that leaders faced within their organizations in addressing workforce health. The third theme was organizational culture. The fourth theme was the responsibility of the organization to take care of their workers. The fifth theme was the need for the training of workers and supervisors specifically related to trauma-informed practice and ameliorating vicarious trauma in workers. The sixth theme related to the supervision of workers and the seventh theme was related to resources. This study attempted to address the gap regarding exploring the experiences of those who were exposed to secondary trauma and what measures were in place from an organizational standpoint to alleviate some of that strain. It would be interesting to get the frontline workers' perspective on this subject, as opposed to the administrators speaking on behalf of the frontline workers. The frontline workers would have been able to add more depth and provide more opportunities for the research community to understand how they experienced the organizations' attempts to address VT. Hopwood, Shutte, and Loi (2019) also stated that burnout might be a phenomenon experienced by other frontline workers. It would be noteworthy to attain how the youth worker perspective, experience and coping styles might be able to speak to and/or add to the burnout/support conversations.

When conducting this literature review, it was evident that a significant number of the research studies relating to the impacts of exposure to trauma on frontline social service 
providers professionals and caregivers adopted theoretical frameworks embedded in the disciplines that have origins in positivist paradigms (e.g., sociology and psychology). For example, Hopwood et al. (2018), utilized the conservation of resources (COR) theory to examine secondary traumatic stress; a theory based in the discipline of psychology. To provide some context, positivism is grounded in the belief that reality, people's experiences are essentially comprised of social facts that can be measured (Creswell, 2014). Emile Durkheim, and other modern thought leaders, believed that reality could essentially be observed and measured, and Durkheim would utilize this approach to establish the study of sociology (Creswell, 2014). By relying heavily on data, researchers remain distant from the subject which was being observed. The core premise was that reality is "out there" and that through rigorous scientific experiments and natural laws, human responses could ultimately be determined and measured objectively. Given the complexity of human behaviour and the multitude of social conditions that may impact individuals, it is imperative to utilize postpositive theoretical frameworks. The Hopwood et al. (2018), study effectively links the impact that working with vulnerable populations may have on youth workers' mental health, to potentially higher risks of burnout; but called for a clearer understanding that reduced both ATR and compassion fatigue.

While there is a plethora of literature outlining the health impacts of exposure to community violence, there is a paucity of literature on how this impacts Black social workers in the Canadian context. As a researcher, this leads me to inquire about the voices that are missing in these studies. This is where qualitative narrative inquiries have the ability to provide deeper context into complex issues faced by the youth workers. It would be interesting to explore what the youth workers' organization/workplace was doing to lessen or address their levels of 
depression, anxiety, and stress, and how youth workers were being made to access those supports.

Though the literature in this area was very informative, the voices and experiences of those who work with clients and patients who experience trauma still managed to be muted, either by quantitative research methodologies or by those with organizational power who spoke on their behalf. The muted voices added to the gaps needed to address workplace and policy supports (or lack thereof) for frontline workers to continue to support youth and others who endure trauma, while also attending to their own mental health. This lends to the importance of creating research that empowers the voices and explores the experiences of those who serve populations that experience trauma. Anti-Black racism and critical race theoretical frameworks can help to create platforms where these voices can be heard.

\section{THEORETICAL FRAMEWORK}

This chapter will explain my rationale for utilizing anti-Black racism and Critical Race Theory (CRT) as the theoretical frameworks that guide the critical analysis, as well as outline the concepts and tenants that underline the theory and areas of focus for this major research. In addition, this chapter will examine anti-Black racism in the broader context of anti-racism praxis whilst directly making the connection to autoethnographic research as a Black male social worker in relation to community violence and mental health impacts. For the purpose of this major research paper, it is essential to define anti-Black racism and explain the theory's components, historical roots and underpinnings of anti-racism and colonialism.

\section{Rationale}


In conducting the literature review many of the studies were based in theoretical frameworks rooted in positivist social science paradigms. To provide some context, early social science research was grounded in positivist paradigms and provided the framework for disciplines such as sociology and psychology. Early social scientists sought to develop objective and rigorous methods to measure human behaviour in a similar manner to which natural science embraced measurement. Thus, early social sciences were dominated by data driven quantitative studies and positioned human behaviour as observable, predictable, and patterned (Neuman, 2011). This autoethnographic research study seeks to move beyond rigour and objectivity and explore the subjectivity within dominant discourses of mental health impacts on frontline social service professionals exposed to community violence.

The decision to utilize anti-Black racism and Critical Race Theory is grounded in the intention to contribute a critical race perspective to existing research on exposure to community violence and mental health impacts, in relation to social work practice.

\section{Anti- Black Racism}

Mullings, Morgan and Quelleng (2016, p. 23) define anti-Black racism as "prejudice, stereotyping and discrimination that is directed at people of African descent and is rooted in their unique history and experience of enslavement”. Mullings, Morgan and Quelleng (2016) describe anti-Black racism in Canada as being often subtle. Although it is not generally expressed with overt racial slurs or explicitly prohibitive legislation, it is deeply entrenched in Canadian institutions, policies and practices (Mullings, Morgan \& Quelleng, 2016).

Kumsa, M'Carthy, Oba and Gaasim (2014) assert that anti-Black racism has at least three distinguishable forms that explain how it is embodied and how it manifests itself in anti- 
oppressive practice. The most common form of anti-Black racism (A-BR), can be outlined as the type of racism directed against Black peoples. This form of A-BR can be described as a form of structural violence (Kumsa, M'Carthy, Oba \& Gaasim, 2014). This is best understood when we examine unequal treatment of Black people in the school, justice and health care systems, to name a few. This definition speaks specifically to violence and its' manifestations in governmental policies, law and systems directly impacting the health and well-being of Black communities. In my experience as a long-standing social service provider, structural violence is the most ambiguous, oppressive and has the greatest impact on health outcomes of the Black community. McKittirick (2011) poignantly states "anti-Black violence within the Americas is, of course, bound up in a range of death-dealing activities: the subtleties of slow bloodless genocides, imprisonment, racial profiling and police brutalities, poverty, environmental racism, and community bloodshed" (p. 952).

Crichlow (2014) asserts that structural violence directly impacts Black youth and families. Throughout my career I have worked with many young Black men who have experienced trauma as a result of their interactions with police. When discussing the issues of police brutality, racial profiling in relation to anti-Black racism and Black communities, it is imperative to critically examine the notion of white supremacy. To provide some context, white supremacy can be described as policies and practices, positioning whiteness as acceptable, while simultaneously positioning racialized people's as societal threats (Phillips \& Pon, 2018). Within the historical context of the institution of slavery, the strategic positioning 'othering' of the black body gave way to the justification and acceptance of profiling of black bodies.

According to Kumsa, M'Carthy, Oba and Gaasim (2014), the second form of antiBlack-racism (AB-R), can be defined as the type of racism that Black peoples perpetuate. In this 
section, the authors brilliantly reference Fanon as a theorist that has critically examined this phenomenon. The authors provide a salient quote, "as if the anti-Black racism we struggle with from "out there" was not harsh enough, we have to wage our anti-oppressive struggle against our own Black racism as well" (Kumsa, M'Carthy, Oba \& Gaasim, 2014, p. 27)

Lastly, anti-Black- racism (A-B-R) means both the struggle against anti-Black racism and the struggle against the racism perpetuated by Blacks. The two previous forms of anti-Black racism are not mutually exclusive (Kumsa, M'Carthy, Oba \& Gaasim, 2014, pg.27). If we study oppression of Black people at both global and local contexts, the authors contend that they in fact reinforce each other, further marginalizing Black youth. According to Mullings, Morgan and Quelleng (2016), anti-Black racism is either functionally normalized or rendered invisible to the larger white society. They submit that "Canadian anti-Black racism in its contemporary form continues the historical practices of racial segregation, economic disadvantage and social division. Essentially anti-Black racism adopts a critical lens to anti-racism specifically focusing on the black peoples" (p. 23).

\section{Critical Race Theory}

I chose to use Critical Race Theory (CRT) because it looks at the relationships between race, racism and power while taking into account existing variables such as context, economics, gender and history (Delgado \& Stefanic, 2012). Critical Race Theory provides an overall framework to help articulate how anti-Black racism is embedded in society and how it impacts Black communities. Critical race theory understands racism as ordinary and active in the institutions and power structures under which our society exists (Delgado \& Stefanic, 2012). Ontario has had a complex and long-standing history with racism, and anti-Black racism. James 
and Turner (2017) point out that although contemporary governments have come to acknowledge the inequities that are particular to Black peoples in Ontario (and Canada), the racism embedded within the very structure of Canadian systems and institutions combine in ways that reinforce the unequal treatment experienced in Canadian society. This framework helps to substantiate and legitimize how anti-Black racism is taken up in society and has created a method in which Black narratives help to create more equity through counter-narratives. My ethnographic approach will be rooted in the counter-narrative aspect of the critical race theoretical framework.

\section{METHODOLOGY}

Throughout the development of this paper, it became evident that identifying one's research paradigm was fundamental in giving context to the rationale behind the methodology. Through engaging in readings and discussions it became evident that methodology and epistemology play a pivotal role in the construction of knowledge and how we approach research. Epistemology can be understood as both the justification and theory of knowledge (Carter \& Little, 2007). In designing this research framework, I chose autoethnography as the research approach with the hope of providing insight into my experiences, specifically as it relates to my cultural experiences. By using myself as the subject my intention is to provide the reader with a broader context that informs my experience (Pitard,2016).

Narrative inquiry approaches to research allow for an exploration of deeper meaning and context within an individual's life. By listening to individuals' stories and engaging in discourse analysis, narrative inquiry allows researchers to be able to identify the themes and structures that have shaped the individual's life (Chase, 2003). Drawing from the rich history of qualitative narrative inquiry, this major research paper utilizes autoethnographic approach. Walcott (1999) defines autoethnography as being the study of oneself while in the process of observing and 
assessing a social context in which the self is situated. I chose this approach because of the opportunity to use my narrative to centre the Black social service worker experiences and voice juxtaposed with anti-Black racism. Autoethnography is a narrative inquiry that can be used to gain insight into the beliefs, norms and of a cultural group. Ellis, Adams and Bochner (2011) repeatedly describe autoethnography as a "cultural" systemic method to analyze personal experiences in order to gain a deeper understanding of one's cultural experience. Additionally, Chang (2008) argues that autoethnographic research creates and provides the space needed to make connections between culture, the researcher-self, and the other. In addition to narration, engaging in autoethnography allows the researcher to actively engage in cultural analysis and interpretation (Chang 2008).

As a Black man, my positionality allows me to provide oppositional narratives to the dominant ideologies concerning Black youth, community violence, trauma and healing discourses. Ellis (2004) states that "autoethnography refers to writing about the personal and its' relationship to the culture" (p. 37). As a researcher, my intention is to bring a voice to the experience of community violence from the perspective of a Black social service worker. As mentioned earlier in this paper, the experiences of Black social service workers in a Canadian context, are too often omitted from dominant discourses. It is important to challenge dominant discourses, and narrative approaches to inquiry have a unique ability to critically examine issues of identity and power.

It is important to note that some scholars have begun to challenge the notion of subjectivity in critical autoethnography research paradigms. Most notably Madison (2020) cited Noblit and colleagues (2004), stating that much of critical ethnography focused on social change but neglected to focus on the researcher's own positionality (p. 7). Similar to critiques of the so- 
called "objectivity" of positivist research, critical ethnography must also challenge the notion of subjectivity within research studies (Madison, 2020). For this reason, I pay extra attention in this paper to engage with the process of acknowledging my own positionality, how my social location contributes to epistemology and how that impacts the analysis of this research. This is in line with Madison (2020) who submits that through engaging in the process of positionality, ethnography can contribute to emancipatory knowledge and discourses of social justice.

\section{Locating Myself}

Over the last fifteen years, I have dedicated my life to engaging Black youth from marginalized communities. I believe that my passion to support these young people can largely be attributed to my ability to relate to many of their experiences. My ability to not only relate to racialized youth, but also to be in a position where I am able to offer effective support, stems from my personal experience of walking both of those lines. In retrospect, perhaps it was my own social location and experience that inspired me to dedicate my life's work to impacting youth in this manner. I have always wanted to create spaces where Black youth would have options other than what society wanted for them; and decided early on to pursue a career in social services.

\section{TRANSFORMATIVE EVENTS AND ANALYSES}

Kumsa, M'Carthy, Oba and Gaasim's (2014) method of reflection and analysis of how anti-Back racism impacts their work, is the inspiration of how I will conduct my analyses. Their article entitled "The Contours of Anti-Black Racism: Engaging Anti-Oppression from Embodied Spaces" is a critical reflection of embodied tensions of anti-Black racism written by the four aforementioned researchers. The authors begin the article by locating themselves as four Black individuals from an Ontario University. They identify as Africans from the continent who 
came to Canada with their families as immigrants or as refugees (Kumsa, M'Carthy, Oba, \& Gaasim, 2014). To provide some context, the authors decided to write the article after engaging in a research project examining the escalation of gun violence and the disproportionate impact it has on racialized youth. After completing the project, the authors came to what they describe as a reflective realization. They explain that they were "inextricably woven into the tangled web of anti-Black racism even as [they] were struggling to disentangle [themselves] and break free (Kumsa, M'Carthy, Oba, \& Gaasim, 2014, p. 21).

This statement puts into words the way that I have come to understand my own experiences. This analysis will attempt to articulate a deeper understanding of how the entanglement of anti-Black racism impacts Black social service workers. I will analyze my experiences using the themes that were explicit in some of the studies in the literature review: 1) exposure to community violence, and 2) mental health and work.

The National Child Traumatic Stress Network (2019) defines community violence as intentional acts of interpersonal violence often committed in public areas by individuals who are not intimately related to the victim (p. 1). Although this definition is most commonly used to describe violence amongst groups and gangs that involve the use of weapons and public shootings (City of Toronto, 2019), for the context of my analyses, I will also broaden this definition to include the violence that the Black youth communities endure from societal, political and institutional levels. I will then observe how anti-Black racism engages with these themes to explore my research question: How does anti-Black racism impact my experience as a black male social worker supporting black youth and families living in communities that experience community violence? 


\section{Transformative Event \#1: Racial Profiling and Structural Violence}

In 2006, I worked as a social service worker in a community agency based in one of the largest and oldest social housing communities in Toronto, Canada. This vibrant community primarily was comprised of racialized newcomer families with a high concentration of Black families. In my role as the local social service worker I hosted a weekly Friday night drop-in program entitled "Dinner and A Movie". The program would typically have 40-50 youth between the ages of 13-17 preparing and partaking in a meal together. Dinner would be followed by a movie, which would then lead to dynamic discussions about the themes of the movie amongst the group.

On one particular evening, I noticed that a particular group of the older youth were not in attendance. I began to inquire with the other youth about their whereabouts. Shortly after my initial inquiry I received a phone call from one the parents of the youth. The parent stated that her son and several other youths were arrested and had been taken away by local police officers in cruisers. In response, I called the local division in order to determine the nature of the charges which had led to the arrest of the youth. Shortly after, several of the youth's parents and I made our way to the police station. At that time, we were informed that the youth had been charged with a possession of a controlled substance with intent to traffic. Unfortunately, the boys were held overnight in order to appear before the court in the morning.

The following day, I accompanied the family to court in order to offer support through the bail hearing process. As I watched the boys enter the court room handcuffed and escorted by the court officers, I saw the trepidation in their faces as they were placed into the holding box to address the charges with the presiding Justice of the Peace. As the youth entered the box, 
wearing the same clothes that they had on the previous day, I began to wonder about their basic hygiene and whether or not the youth had eaten since being arrested.

The bail hearing began by the crown attorney reading out the names of the youth while outlining their accompanying charges. I sat carefully listening to the charges being read. Possession of a controlled substance with intention to traffic did not sound like the youth that I had come to know through my program. These youth regularly attended the drop-in program and actively participated in every aspect of programming. I continued to scan the court and realized that all of the court officials were non-racialized. In the eyes of the court the young men were drug dealers and their punishment would be reflective of this subjective interpretation.

Finally, after several hours of court proceedings the three youth were released with numerous bail conditions. The conditions were ones that were often associated with individuals believed to be involved in drug trafficking. As surety for the youth, they were able to attend my program. In speaking to the youth regarding all that had transpired, they disclosed that on the evening in question they collectively made a decision to purchase marijuana with the intention of smoking together at the local school before attending program that evening. Shortly after arriving at the school yard, the youth stated that they were approached by local police on bike patrol. They were immediately placed into handcuffs and subsequently searched. That was when the police found the marijuana they had purchased with the intention of smoking collectively. The amount that was found was a small quantity, and not enough to justify the charges of trafficking.

\section{Analysis - Transformative Event \#1: Racial Profiling and Structural Violence Theme A: Exposure to community violence.}


As I reflect back on the Dinner and Movie program, I first contemplate about why it was important to create such a program on Friday nights in the first place. With the budget cuts over the years around quality extra-curricular school programs, many youths in urban areas were left to figure out their after-school schedules on their own. In this particular community, filled with hard-working newcomer populations, it became increasingly difficult for parents to manage to be home right after school. Many parents had to work two or more jobs to make ends meet, and that usually meant that they were still working when the children were finished school. Youth often wanted to hang out together after school and with no real place to congregate on their own and very limited green space in housing communities, they often would have no other choice than to hang out on the sidewalks, parking lots or on street corners.

Anti-Black racism engages with policy here to create and exacerbate precarious conditions for social and community development of Black youth and their communities. Here we see how these cuts impact racialized areas, highlighting the lack of resources for youth. These cuts and lack of program resources emphasized that implications for Black youth living in housing complexes were far more layered than for their white peers living in suburban areas of the city. Crichlow (2014) asserts, Toronto's social housing communities exacerbate the feeling of hopelessness and are a form of social control for black youth being raised in prison like conditions. A group of youth hanging out in their neighbourhood on a Friday evening carried far more consequences than a group of white peers doing the same. Racial stereotypes of criminality and aggression towards Black people are projected more than other racialized groups (Miller, Manner \& Becker, 2010).

I would like to draw attention to the image of groups of Black youth congregating in public spaces. This image has been painted and tainted by dominant culture to mean something 
negative, something menacing. Both the ideas of public space and the meanings attached to Black bodies need to be addressed and challenged. According to Mills (1997), the white social contract categorizes space as post sociopolitical (civil society) and those outside of the white social contract (non-whites) who might occupy these spaces are seen as alien. As Black peoples continue to be "othered" by dominant discourses and historically seen as "savages", public spaces meant for the "civilized" dominant culture, means that Black peoples do not belong (Mill, 1997). Congregations of Black people in these public spaces which were originally meant for white people becomes threatening. How many Black bodies are considered too many for a public space? In recent events, we see for Ahmaud Arberyis and Trayvon Martin, one was too many.

This image of groups of Black youth congregating feeds into the media portrayal of Black bodies as suspicious and as a threat to harmony. Morgan, Mullings, and Quelleng (2016) submit that the ways in which the media portrays Black bodies helps to shape discourses that Black men cause social problems and threaten the safety of "White Canadian society" (p. 26). Baldridge (2011) states that Black males are framed as "civic threats that warrant containment and policing" (p. 124). This portrayal of the menacing Black youth is violent. Morgan, Mullings and Quelleng (2016) argue that although violence is present within all communities, the media uses racial stereotypes in addition to over publicizing and over reporting violence in black communities. This perpetuates the portrayal of Black men as inferior, as suspects and as outsiders (Mullings, Morgan, \& Quelleng, 2016).

Mullings, Morgan and Quelleng (2016) affirm that "policing techniques and activities of racial profiling are used to stereotype, stigmatize, harass and discriminate against African 
Canadians" (p. 25). In this particular case, these boys were handcuffed and then searched.

Rankin (2012) states that young black males are disproportionately carded at higher rates than other populations. The sequence of events is very important here as the police did not have any reason for handcuffing these three-youth other than the fact that they were Black and hanging out in a public space. The sequence also speaks to the police's lack of respect for these youth, that these Black youth did not even merit the following of proper police protocol. The police felt justified in their actions, though illegal, because it fed into the narrative of the threatening Black youth who have nothing better to do with themselves than to cause social problems (Morgan, Mullings, \& Quelleng, 2016).

During the court case, there was no real defense for these boys. They were treated as criminals from the start. There was no real inquiry about the process, or why they were arrested. The narrative about the Black drug dealer menacing the streets was such an easy buy-in for the police, courts and justice system. No one bothered to ask if there might have been another explanation. Given the context and the historical strain between policing and Black people, still no one thought it was important to question the initial charges. These youth were not seen as a few kids who were getting together to smoke marijuana, they were seen as criminals right from the start, even though the facts suggested otherwise.

\section{Theme B: Mental health and work}

The Dinner and Movie program was the community centre's way of creating a safe space for youth confronted with this violence. I designed the program to be a space that understood how the anti-Black racism implicit in policies and budget cuts impacted the minutia of youth lives, every day. When I reflect back to how I delivered that program, I made it my business to 
get to know and develop relationships with all of the 40-50 youth who attended. I wanted to know what they spent their time doing outside of the program and how to make the program more engaging for them. We didn't just order food, we also prepared and made a menu, cooked, conversed, laughed and ate together. The movies were entertaining, and we talked about them at length. I helped them develop their critical lens. The youth found a platform where their voices were heard and where their opinions counted. I remember looking around the room and feeling really happy and relieved that we had managed to create a safe space for these youth.

At first, the program was funded, but when funding ran out, I became worried. During our time together many of the youth had told me that the program had become a safe space and they regarded our time together as an extension of their family. So many "beefs" were squashed, conflicts were defused, and familial bonds were made within our program walls. I remember feeling pressure to try to get more funds to keep the program running, but with budget cuts and so many other organizations vying for the same grant money, it was impossible. I recall feeling defeated, but I just couldn't let the youth down. I began funding the program from my own pocket. This is not unusual in the Black community. In my 20 years working in community, I have noted that there are such limited resources for programming that community workers often dip into their own pockets to ensure that the program is successful, and that youth are supported.

At this time in my life, this was challenging to do. I had a family and was getting paid minimum wage. I would budget for my family and the weekly program that fed 40-50 youth, and I remember feeling a lack of support. I felt that the community centre was unable to offer the supports that I needed. There were no support staff. Sick days meant that if I called in, there was no program, or I would not get paid for the time away. I felt a lot of pressure to be there for the youth, and it was the first time I remember feeling hyper-extended, but I pushed through. In 
retrospect, I know that I put a lot of undue pressure on myself, but I also did not want to let any of the youth down. I took that job knowing the challenges regarding lack of resources and I really wanted to make a difference. I walked the line of remembering what it was to be a Black youth and wanting to have a welcoming space for myself. I saw myself in many of the youth and I wanted to provide for them, what I thought I might have needed when I was a young person. My positionality and social location played an integral part in my willingness to put so much of myself into the program.

When I noticed that a group of youth were not present in the program, I began to inquire about their whereabouts because I knew about all of the barriers that anti-Black racism posed for the youth, especially in that community. The community had heavy surveillance and the police had a history of not being very welcoming to the racialized youth in the area. Morgan, Mullings and Quelleng (2016) assert that “African Canadians are subjected to heightened scrutiny by police and have their communities and lives disproportionately monitored by the police and policing activities" (p. 29-30).

I remember feeling pulled because as I was asking the other youth in the program, I didn't want to alert them to anything, or ruin their time there by being worried. As I smiled and joked with the youth in the program, I kept thinking about the youth who were missing and was going over what would happen if I was needed. Who would run the program while I was gone? Will the youth have time to eat dinner before I would have to leave? Again, I felt this pulling in multiple directions, but I had to figure it out on my own.

When I received the call from the parents confirming my initial worry, thankfully, the program was over. They asked if I could go to the station with them. I offered support and had to figure out how best to be helpful to the youth and to the family. There is no real preparation 
for these types of situations, nor the emotions that bubble up because of them. My power and privilege were really highlighted in this situation. On the one hand, I was able to offer some support to the family by being a legal surety for the youth. That means that as part of their bail conditions, they would be allowed to attend program with me. On the other hand, I felt helpless, especially after learning what really transpired between the police and the youth. I wanted to do

more, but really could not do much at all. I was not a witness to the facts, and it would have been their word (the white police officers) against mine (a Black program manager).

\section{Transformative Event \#2: Youth Supports}

Que (pseudonym) was a 13-year-old Black boy attending the youth programs at the community centre. I was particularly drawn to Que because he was a quiet boy, however, he was extremely charismatic, and intelligent. Anytime Que opened his mouth to speak he easily commanded the room, always carefully articulating his views.

One day at school, Que was involved in a verbal argument with another student which unfortunately escalated to a physical incident. According to several witnesses, Que was upset with his classmate after he learned that the student intercepted a note he sent to another student during class. The content of the note was a request to attend the upcoming school dance as his date. As a result of the fight, Que punched the student and was subsequently sent to the office. In response to the incident, the school principal decided to press charges and called the police. I would later learn from staff and parent volunteers that the principal and police officers desired to make an example of Que. Instead of notifying or involving Que's parents and/or community workers (which was common practice in that school for minors), the police arrested him. In 
addition to arresting him, the officers decided to wait until recess time to walk him out in handcuffs in front of the entire school. We worked with Que's family to arrange release.

The next incident took place when Que got into an argument at the local basketball court which escalated into a fight. During the fight the other young man dropped his cell phone and although Que had not taken the cell phone, he was charged with robbery. These were his first two charges, and he would subsequently go on to spend the next 8 years of his life in and out of jail, out for no more than 3 months at a time. Over the years I made it a point to keep in contact with Que and we communicated while he was in jail. When released, he would often come out to the community centre and I would support him in achieving the goals he had for himself around employment.

In 2013, Que was released from prison at the age of 23 and began to take the steps to turn his life around. After successfully finding employment and working in a steady job for five months or so, he asked to meet with me in order to help him fill out an apprenticeship program application in an effort to be able to access a higher position or higher paying job to support his growing family. He came to see me on a Wednesday, and we talked about his future aspirations. I helped him fill out the apprenticeship application and I remember how proud I was of all the work he was doing to get himself on the right track.

Two days later he went out to celebrate the fact that he had completed the apprenticeship application and that he was going to be a father for the first time very shortly. He had taken the proper steps and was encouraged by how quickly things had been moving in a positive direction. Things were good for him and he was finally happy again. 
Unfortunately, that Friday night, he ran into somebody that he had met during his time in prison and while smoking a cigarette on the balcony, he was shot in his head 3 times. Que would be pronounced dead at the scene.

\section{Analysis - Transformative Event \#2: Youth Supports Theme A: Exposure to community violence.}

“...African Canadians are punished in various ways; they are beaten, brutalized, sexualized, shot, killed, imprisoned, detained, separated, expelled, suspended, isolated, searched, targeted and denied” (Mullings, Morgan, \& Quelleng, 2016, p. 29). This aligns with Aymer's (2016) study which outlines how Black male adolescents cope with life-course developmental challenges, in addition to having to deal with "the toxins from racial oppression in the social environment that ultimately impinge on their positionality" (Aymer, 2016). At a very young age, Que had his first real encounter with how the violence of anti-Black racism engages with the school system. Carl James, in writing about black boys and schooling states, “...stereotypes of Black males - immigrants, fatherless, athletes, troublemakers, and underachievers- operate to categorize essentialize and disenfranchise young Black male students as they navigate and negotiate the school system" (James, 2012, p.471). The "Black boy threat/troublemaker" narrative was amplified when the police were called in to a school to arrest a 13-year-old boy for a fight. In that moment, the dominant discourses that upheld Black bodies as violent, aggressive and criminal superseded the fact that he was just an elementary school boy. It ignored the fact that there might have been other ways to address the situation, where other adults and professionals could have been called instead of the police. It dismissed the fact that the fight was between two people and yet, only the Black boy got arrested. It discounted the harm that could imprint on a young, developing person and the societal realities that the implications of such an 
experience would mean for years to come. Its disregarded policy, protocol and decency in order to make an example of what Black bodies can expect when in public spaces. According to James (2012) "the racialized script that Black males are expected to follow is one 'designed within white society's projected fears of Black manhood, not the self-determined efforts, experiences and potential of Black manhood" (p. 470; also see Stevenson, 2004; Walcott, 2009). As a black man it is psychologically exhausting to navigate space in a society that dehumanizes my black body while constantly perceiving me as a threat. Morgan \& Quelleng and Mullings (2016) poignantly states, “[...] The black Canadian man is that of a dangerous, hostile and uncivilized beast that must be captured and destroyed" (p. 33).

Que told me that this experience changed how he viewed himself and how he viewed the world. He no longer believed in fair processes or justice. He told me that being escorted out through the yard like a criminal in handcuffs by police in front of all of his peers - the boy who he was in a fight with who snickered at him as he went by, his teachers and principal who called the police in the first place — was very hard for him. He said that being treated like a "bad guy", when he didn't feel like he was, and having to endure a punishment that far exceeded his offence without any question or regard for his side of the story, made him realize that it didn't matter how he saw himself, because the world would make him out to be whatever they saw him to be. James (2012) describes a study where groups of Black students felt that they were being racially profiled by their school, that teachers and administrators routinely were "disrespectful, did not take into account circumstances into account when dealing with their actions and often felt that the school "delivered them to the judicial system" (p. 481). James (2012) documents a Grade 11 student who felt that teachers treated Black students differently and expected that Black students would cause trouble or do bad things. 
In one of my conversations with Que over the years, he confessed that after a series of those types of events, he decided that if he was going to be viewed as a bad guy and punished as the "bad guy", he might as well have become the "bad guy". Que began to acquaint himself with gangs and began to play out the roles that had initially been projected upon him. During his time in and out of jail, he would contact me. He confided in me and expressed that he was conflicted. He didn't want to walk the path that had landed in him jail, but often felt that there was no other real option for him anymore. He felt that there wasn't any real support and believed that he wouldn't be afforded a real chance to be able to change his circumstances. This speaks to the lack of resources in racialized communities and the school to prison pipeline that Black males experience more frequently than many of their peers (James, 2012).

\section{Theme B: Mental health and work}

Que's trajectory in life has always stayed with me. Like many of the youth I have supported throughout the years, Que and I developed a relationship beyond the scope of just a drop-in program at the centre. Because I shared the social location of many of the youth who came through my program, although I was an authority figure, I was relatable to them. I was able to see my younger self in many of their struggles and I wanted to use my position and privilege to provide some supports. They trusted that I always had their best interest in mind, and I really did my best to support them, making sure that they felt heard and felt seen. Many of the youth who came to my program regarded me as an extension of their family, and the feeling was mutual.

I paid special attention to Que. He was quiet, but observant and so articulate. I remember trying to nurture those parts of him and would try to bolster his confidence. When I heard what 
had happened at his school, and then at the court, I was so angry. I was angry that he had to experience such a harsh reality at such a young age; the reality that stole his innocence and told him that he was inferior, disposable and threatening all at the same time. In retrospect, I think that Que assuming the role of "bad guy" was his way of resistance. When I sift through everything that he said and everything that he did, he sounded tired of being accused of being a label that he didn't associate with. He got tired of having to try to prove that he was no more at fault than the other guy, that he wasn't as bad as they made him out to be, that he wasn't inherently violent, and that he wasn't a threat. He was tired of his efforts being dismissed and his voice being silenced. In one of our later conversations, he told me that assuming the roles that were initially projected onto him was his way of taking control of his narrative. Up until that point, he felt that his "otherness" defined by white society was dictating his narrative.

I remember how much those words hit home for me. I was once a Black male youth, and many of those narratives were projected onto me as well. Helping someone navigate anti-Black racism while facing it myself in many areas of my life was challenging. Again, I felt like I was walking a very fine line between power and privilege and perhaps helplessness. Although I was an authority figure to Que and he looked to me to answer some really important questions, I just could not because I didn't know the answers to them all. As a Black man, I too was navigating anti-Black racism and the violence surrounding my work and my relationships with police, schools, youth and their families. The best I could do was to let him know that he did have options and that I supported him in exploring the positive ones. At this point, I had become emotionally invested in seeing Que come out on the other side of this. I wanted to see him happy and enjoying the positive choices that he made. 
While Que was in and out of jail, I had already lost a few youths to gun violence. I spent most of my time supporting youth who had lost their friends and family, supporting youth in jails, attending funerals and making sure that everyone was coping well. However, I was not coping well. I had no work benefits that could support me in accessing a professional with whom I could speak with. There was no guidebook that instructed next steps. The work was isolating in that I carried these things with me in addition to my own experiences. I carried the faces, hopes and dreams of all the youth I had known who had lost their lives to gun violence; and after some time, it became heavy. I wondered if I was really helping. I wondered if my programs were effective. I doubted my ability to support the youth and the challenges they faced in their everyday lives. I felt discouraged. Youth were telling me stories about the injustices they endured at school, the racial profiling that happened while walking down the street, their interactions with police and I felt limited in my ability to help. How could I break down the barriers that anti-Black racism built up over time? How could I boost their confidence during program, when the minute they step out, they face a world that tells them they are inferior?

When Que was finally taking the steps to change his life, it gave me hope again. I was excited for him. I was excited for the new life that he would have. However, it all came to a screeching halt when he died before realizing any of it. In my role at the time, I responded to the trauma of the youth who knew him, his family members, and helped organize a BBQ to help raise funds for his funeral. I hadn't allowed myself to grieve. And it was at this BBQ where the pressure I had been feeling for years surfaced and I grieved.

\section{IMPLICATIONS}


In reading some of the literature, it is apparent that supports for front-line workers who are exposed to violence indirectly are lacking (Argentero \& Setti, 2011; Devilly, Wright \& Varker, 2009). It is evident that social workers who directly support populations that experience trauma are susceptible to experiencing negative mental health impacts including vicarious trauma and professional burnout (Singer et al., 2020). This is in line with the themes that emerged from my analyses which includes implications for policy and mental health supports. In analyzing my own experiences working on the frontline to support Black youth experiencing trauma, I found that anti-Black racism engages heavily with policy to perpetuate, reproduce and widen inequities for both the worker, community and the Black youth population being served.

\section{The Context in and around the Workplace}

Anti-Black racism can impact Black service workers who serve Black youth in underserved communities through the policies that impact their workplace. In the analysis of Transformative Event \#1: Racial Profiling and Structural Violence, this phenomenon remained evident. Many of these policies inform funding and subsequently, the functionality of the workplace/organization which contributes to inadequate financial, educational and mental health supports for their front-line workers.

There is a small and limited pool of funding for not-for-profit organizations whose expertise lie in supporting Black youth communities. This funding is competitive, and many organizations allocate their available resources toward developing programs to support the populations that they serve. In marginalized areas, resources are scarce and program development is very acute. That is, programs are developed to address a specific concern or provide a specific service. In an effort to address racial profiling, and community violence the 
Dinner and Movie program sought to provide an accessible space for youth between 13-17 years of age in the community. Starting from a point where community resources are already scarce, there is rarely any additional room to consider building in supports for the actual worker who is to deliver the program and/or who interfaces with the population being served. Without front-line workers who willingly wear many different hats (i.e., counsellor, program staff, grant writer, fund manager, program coordinator, community liaison, family mediator and so on) in order to provide better supports for the youth, organizational programs and services might not be as successful (see Froyum, 2013).

The intention was to engage the youth with the hope of fostering a greater understanding about how to we could navigate various forms of violence.

The program was initially conceived because the organization understood that there was a great need to create a space for the 13-17-year old youth in the area. Every part of the budget for funding went into programming; most went into food, the rest into movie rentals and general program expenses. During the time in which this program operated, I came to the realization that the organization lacked resources to provide support beyond basic program expenses.

As the program gained traction, the number of youths who attended the program grew, with most participants being between the ages of 16-17. The original funding amount was thin to begin with, and once the number of participants grew, it accelerated the process of the funding running out. I found myself placing more and more of my own money into the program in order to supplement the amount needed to support the additional youth who came; and then even more in order for the program to continue once funding had officially ended. No one ever asked any questions as to how the program was still running, or what was needed to ensure that it continued 
to run smoothly. This situation was not unique to my experience. Many of my peers who worked in other communities and who ran programs for Black youth in densely populated areas, reported that they were doing the same thing. It was either they supplemented the program, or the program youth would suffer. Workers often go above and beyond their role of employment in order to ensure that the children are well-supported. Froyum (2013) reported that "workers created a 'home' or 'family' at work by integrating children into their emotional lives and making themselves readily available" (Froyum, 2013, p. 1077). The way anti-Black racism engages with Black communities to produce a lack of resources, lower socio-economic conditions, and the needs of Black youth, impacts how Black service providers engages with youth populations because they often use their own means and resources (emotional, psychological and financial) to account for the visible lack.

This has many implications for policies surrounding funding for communities facing additional barriers to serving marginalized populations. The first is gaining governmental (municipal, provincial and/or federal) support for organizations situated in areas that are marginalized and at a socio-economic disadvantage. These municipalities and their community organizations should receive funds in order to create equity so that targeted programs are not already starting from a disadvantage. Thus, the implications of lack of adequate funding greatly impacts' marginalized black youth and the organizations and frontlines workers providing programming support.

\section{POLICING}


It is important to examine how anti-Black racism engages with policies around increased policing in Black communities to produce and exacerbate the conditions of violence, putting further strain on the already limited resources that help to support Black youth.

In the analysis of the Transformative Event \#2: Youth Supports, we see how quickly the police and justice system were introduced to a fight that occurred between two 13year old's in a school context, but only Que, the Black child, was arrested. Baldridge (2011) states that Black males are viewed as dangerous and are routinely targeted in school. Que's second interaction with the police occurs after a fight at the basketball court, and he gets arrested again, but the police added a charge that was incorrect. In Transformative Event \#1: Racial Profiling and Structural Violence, Black youth were targeted, handcuffed before getting searched, and then they were arrested. They also acquired charges that were incorrect. Embedded in both of these transformative events, is a contentious relationship between Black youth and police, fostered by racial profiling. Racial profiling can be explained using the labeling perspective (Aymer, 2016). "The labeling perspective is an outgrowth of a longstanding belief system that Black people are criminals, despite the lack of empirical data to substantiate such a claim" (Aymer 2016, p. 369). Aymer (2016) states that the racial profiling of Black males by the police undercuts their quality of life and physical well-being. Aymer (2016) further argues that "Black men are disproportionately profiled in society, and this cultivates an indelible stain of marginalization, causing others to devalue their dignity" (p. 369). The devaluation of dignity can also be applied to Black youth workers who grapple with their power and privilege in the face of anti-Black racism, advocacy and supporting Black youth. The perceived shared positionality between the Black youth and the Black service worker subjects them both to "stereotypic assumptions that an entire group is inclined to commit crimes" (Aymer, 2016, p. 369). 
It is important to note that the over-policing of Black communities has never helped Black communities; it has, however, helped white conservative populations feel "safe".

Over policing and racial profiling has only led to an over-representation of young Black males in prisons and jails, increased police brutality and increased fatalities among this population of youth (Khenti, 2018). To have access to statistics, case studies and empirical evidence that show a negative correlation between policing and Black community health, safety and development, yet live in a society that still pushes for increased policing to address violence emphasizes how much anti-Black racism is embedded in the very fibre of society. The underlying issues are not being addressed through policing; therefore, this policy should be addressed, and more funds should be delegated toward supporting communities through programming.

\section{Mental Health}

Walking through the community as a social service worker never shielded me from the imposing suspicions of police, or my heightened awareness of their presence. Many Black service workers go beyond their roles in order to adequately help and support Black youth (Froyum, 2013), however, Black service workers cannot always protect Black youth from the same racial profiling that they themselves face (Aymer, 2016). Navigating our own experiences with anti-Black racism, in addition to supporting Black youth who experience salient, lifechanging interactions with anti-Black racism at various junctures in their lives, requires a lot of mental health support. However, currently there is little to no importance placed on the mental health of Black social service workers who support Black youth and their communities.

For example, most of the social service jobs that Black males occupy do not offer benefits or a pension package. Social service workers or youth workers are usually paid 
minimum wage or just above. They are not given additional training on how to acknowledge or address the trauma that can ensue from working with youth who experience trauma. They are not pointed toward any resources that alleviate any of the additional emotional labour that goes into supporting communities who experience trauma. There are no guidelines or books being circulated on the topics of warning signs or symptoms of vicarious trauma, burn out or depression as a result of this work.

Black social service workers often sit with or push back emotions, in order to keep doing their jobs. On more than one occasion, I remember feeling stretched but I kept going because the work had to be done. I kept going because I didn't feel that there was an option to stop. I kept going because I thought that I would eventually get over the feelings of anxiety and fatigue. I kept going because no one had told me that my mental health was important. Society and the way that organizations are funded and operated, never told me that I, a Black male social service worker, mattered beyond what I brought to the communities. The conversations around the mental health and positive coping strategies of front-line workers never took place. I discovered on my own that if I kept on going, eventually something would change and eventually, I would not be able to continue. After 15 years of stretching, I had PTSD and I burnt out.

I believe what might be helpful for Black social service workers who serve Black youth in underserved communities is training around the importance of mental health and the ways in which anti-Black racism could impact their work. The training could be a municipal program offered by the City of Toronto and could speak to the signs and symptoms of burnout. Therefore, I content that government funding and grants should be developed in order to provide training and accessible mental health support for front line social services workers. 
As many of frontline workers spend much of their time supporting vulnerable populations and communities in the city, it makes sense that the support should be reciprocated and that there should be some way to offer these workers mental health services, supports and check-ins. Benefits and access to mental health supports should be a part of the work. Community tables where youth workers come together to share resources and debrief should be established and regularly attended. This aspect of the work is essential in maintaining overall health and wellbeing and should therefore be recognized, embedded in organizational policy, and effectively compensated as integral part of the work schedule.

\section{CONCLUSION}

In conclusion, anti-Black racism can impact Black social service workers who support Black youth in underserved communities in a variety of ways due to the fact that it is woven into the very fibre of society (Delgado \& Stefanic, 2012). Anti-Black racism catalyzes and layers different meanings to the exposure of violence and the lack of organizational supports that Black social service workers experience.

Anti-Black racism engages with serving Black youth and the communities in which they reside, through increased policing and racial profiling. The relationship between Black youth and police require the Black social service worker to be able to continuously confront their own issues with the experiences they have had with racial profiling; and to try to remain as objective as possible in order to adequately support the youth and their families. It also often means that the lines between power and privilege can oscillate more frequently as the Black social worker confronts the power structures that labels them with the same stereotypes as the Black youth. 
Anti-Black racism is also present in the ways in which the organizations in underserved communities operate. Many of these organizations have a scarcity of resources and they are reliant on small pools of funding that other groups with more resources are also competing for. They depend heavily on intra-community relationships to sustain themselves, but that usually means that people wear multiple hats and perform a myriad of roles. The relationship between stretched budgets and workers who are stretched thin creates higher risk for burnout and other mental health challenges. This heightened opportunity for burnout and other mental health challenges is exacerbated by the lack of benefits and access to mental health supports for Black social service workers.

The analysis of how anti-Black racism impacted my own experiences highlighted the need to revisit policing policies that encourage an increase of police in underserved communities. The analysis points to increased funding to support community resources, more funding for programs that support Black youth, and more ways to support workers through accessible mental health services and peer supports. My analysis also highlights that although anti-Black racism is deeply embedded in our society, there are practical ways that we, as a society, can begin to address them. 


\section{REFERENCE LIST}

Abt, T. (2017). Towards a framework for preventing community violence among youth. Psychology, Health \& Medicine, 22:1, 266-285.

Aden, M., Issa, A., Rayale, S., \& Abokor L. (2018). Another day, Another Janazah: An investigation into violence, homicide and Somali-Canadian youth in Ontario. Youth Leaps.

Argentero, P., \& Setti, I. (2011). Engagement and vicarious traumatization in rescue workers. International Archives of Occupational and Environmental Health, 84(1), 6775. doi:10.1007/s00420-010-0601-8

Assari, S., \& Caldwell, C. H. (2017). Neighborhood safety and major depressive disorder in a national sample of black youth; gender by ethnic differences. Children (Basel, Switzerland), 4(2), 14. doi:10.3390/children4020014

Aymer, S. (2016). "I can't breathe": A case study—Helping black men cope with race related trauma stemming from police killing and brutality. Journal of Human Behavior in the Social Environment, 26(3-4), p.367-376

Baldridge, B., Hill, L. H. \& Davis, J. E. (2011). New possibilities: re(engaging) Black male youth

within community-based educational spaces. Race, Ethnicity and Education 14(1), p.121136.

Bellas, H. C., Jatobá, A., Bulhões, B., Koster, I., Arcuri, R., Burns, C., . . de Carvalho, P. V. R. (2019). Effects of urban violence on primary healthcare: The challenges of community 
health workers in performing house calls in dangerous areas. Journal of Community Health, 44(3), 569-576. doi:10.1007/s10900-019-00657-2

Carter, S. M., \& Little, M. (2007). Justifying knowledge, justifying method, taking action: Epistemologies, methodologies, and methods in qualitative research. Qualitative Health Research, 17(10), 1316-1328. https://doi.org/10.1177/1049732307306927

City of Toronto. (2019). Community violence in Toronto: A public health approach. City of Toronto. http://www.toronto.ca/legdocs/mmis/2019/hl/bgrd/backgroundfile-139315.pdf

Cox, C. B., Johnson, J., \& Coyle, T. (2015). Coping styles moderate the relationships between exposure to community violence and work-related outcomes. Journal of Occupational Health Psychology, 20(3), 348-358. doi:10.1037/a0038556

Cunningham, M. (2003). Impact of trauma work on social work clinicians: Empirical findings. Social Work (New York), 48(4), 451-459. doi:10.1093/sw/48.4.451

Crichlow, W. (2014). Weaponization and prisonization of Toronto's black male youth. International Journal for Crime, Justice and Social Democracy, 3(3), 113-131. doi:10.5204/ijcjsd.v3i3.120

Decker, M. R., Wilcox, H. C., Holliday, C. N., \& Webster, D. W. (2018). An integrated public health approach to interpersonal violence and suicide prevention and response. Public Health Reports, 133(Supplement I). 65S-79S.

Delgado, R., Stefancic, J., \& Harris, A. P. (2017). Critical race theory: An introduction (Third ed.). New York University Press.

Devilly, G. J., Wright, R., \& Varker, T. (2009). Vicarious trauma, secondary traumatic stress or 
simply burnout? Effect of trauma therapy on mental health professionals. Australasian Psychiatry, 43(4), 373-385. doi:10.1080/00048670902721079

Froyum, C. (2013). 'For the betterment of kids who look like me': Professional emotional labour as a racial project. Ethnic and Racial Studies, 36(6), 1070 - 1089. http://dx.doi.org/10.1080/01419870.2011.644309

Hammonds, B. (2019). Vicarious trauma, perceived stress, and self-care among social workers: A quantitative analysis (Order No. 10930823). Available from ProQuest Dissertations \& Theses A\&I; ProQuest Dissertations \& Theses Global. (2138802021). Retrieved from http://ezproxy.lib.ryerson.ca/login?url=https://www-proquestcom.ezproxy.lib.ryerson.ca/docview/2138802021 ?accountid=13631

Hansen-Nord, N. S., Kjaerulf, F., Almendarez, J., Rodas, V. M., \& Castro, J. (2016). Reducing violence in poor urban areas of Honduras by building community resilience through community-based interventions. International Journal of Public Health, 61(8), 935-943. doi:10.1007/s00038-016-0854-4

Hopwood, T. L., Schutte, N. S., \& Loi, N. M. (2019). Stress responses to secondary trauma: Compassion fatigue and anticipatory traumatic reaction among youth workers. The Social Science Journal, 56(3), 337-348. doi:10.1016/j.soscij.2018.08.008

Glover, C., \& Makooie, B. (2018). Exposure to community violence as a social determinant of health. [Motion to the Toronto Board of Health from Trustee Chris Glover]. Retrieved from https://www.toronto.ca/legdocs/mmis/2018/hl/bgrd/backgroundfile-112948.pdf

James, C. (2012). Students at risk: Stereotypes and the schooling of black boys. Urban Education, 47(2), 464-494.

Khenti, A. (2018). Three decades of epidemic black gun homicide victimization in Toronto: 
Analyzing causes and consequences of a criminological approach. Doctoral Dissertation. York University.

Kumsa, M. K., Ng, K., Chambon, A., Maiter, S., \& Yan, M. C. (2013). Rethinking youth violence and healing. Journal of Youth Studies, 16(7), 847-863.

doi:10.1080/13676261.2013.763919

Madison, D. S. (2020). Critical ethnography: Method, ethics, and performance (Third ed.) SAGE.

Margolin, G., Vickerman, K. A., M. A, Oliver, P. H., \& Gordis, E. B. (2010). Violence exposure in multiple interpersonal domains: Cumulative and differential effects. Journal of Adolescent Health, 47(2), 198-205. doi:10.1016/j.jadohealth.2010.01.020

Mills, C. (1997). The racial contract. Cornell University Press

Miller, Saul L., Jon K. Manner, \& Vaughn Becker, D. (2010). Self-protective biases in group categorization: Threat cues shape the psychological boundary between "us" and "them". Journal of Personality and Social Psychology, 99(1): 62.

Mullings, D. V., Morgan, A., \& Quelleng, H. K. (2016). Canada the great white north where anti-black racism thrives: Kicking down the doors and exposing the realities. Phylon (1960), 53(1), 20-41.

Noblit, G. W., Flores, S. Y., \& Murillo, E. G. (2004). Postcritical ethnography: An introduction. Hampton Press.

Pitard, J. (2016). Using vignettes within autoethnography to explore layers of cross-cultural awareness as a teacher. Forum: Qualitative Social research, 17(1) Retrieved from 
http://ezproxy.lib.ryerson.ca/login?url=https://www-proquestcom.ezproxy.lib.ryerson.ca/docview/1797568374?accountid=13631

Pon, G., Gosine, K., \& Phillips, D. (2011). Immediate response: Addressing anti-native and anti-black racism in child welfare. International Journal of Child, Youth \& Family Studies, 2(3), 385-409.

doi:http://dx.doi.org.ezproxy.lib.ryerson.ca/10.18357/ijcyfs23/420117763

Rankin, J., \& Winsa, P. (2012, Mar 10). Known to police: Toronto officers stop, question and document hundreds of thousands each year. young men of colour are 'carded' in numbers far above their population. Toronto Star Retrieved from http://ezproxy.lib.ryerson.ca/login?url=https://www-proquestcom.ezproxy.lib.ryerson.ca/docview/927568156?accountid=13631

Richardson, J. I., National Clearinghouse on Family Violence (Canada), \& Canada. Health Canada. (2001). Guidebook on vicarious trauma: Recommended solutions for antiviolence workers. National Clearinghouse on Family Violence.

Rosenthal, B. S., \& Wilson, W. C. (2003). The association of ecological variables and psychological distress with exposure to community violence among adolescents. Adolescence, 38(151), 459.

Smith, M. E., Sharpe, T. L., Richardson, J., Pahwa, R., Smith, D., \& DeVylder, J. (2019). The impact of secondary exposure to gun violence fatality on mental health outcomes in four urban united states settings. Social Science \& Medicine, 112587. doi:10.1016/j.socscimed.2019.112587

Singer, J., Cummings, C., Moody, S. A., \& Benuto, L. T. (2019;2020;). Reducing burnout, 
vicarious trauma, and secondary traumatic stress through investigating purpose in life in social workers. Journal of Social Work, 20(5), 146801731985305-638.

doi:10.1177/1468017319853057

Stevenson, H. C. (2004). Boys in men's clothing: racial socialization and neighbourhood safety as buffers to hypervulnerability in African American adolescent males. In N. Way \& J. Y. Chu (eds.). Adolescent boys: Exploring diverse cultures of boyhood (pp. 59-77). New York University Press.

The National Child Traumatic Stress Network. (2019). Community violence. Downloaded at: https://www.nctsn.org/what-is-child-trauma/trauma-types/community-violence

Tunstall, D. (2013). Lewis Gordon on anti-black racism. In Doing philosophy personally: Thinking about metaphysics, theism, and antiblack racism (pp. 80-100). Fordham University Press. doi:10.2307/j.ctt13x0ckp.9

Walcott, R. (2009). Reconstructing manhood: Or, the drag of black masculinity. Small Axe, 13(1), 75-89.

Whiting-Blome, W., \& Safadi, N.S. (2016). Shared vicarious trauma and the effects on Palestinian social workers. Illness, Crisis \& Loss, 24(4), 236-260.

Zimmerman, G. M., \& Messner, S. F. (2013). Individual, family background, and contextual explanations of racial and ethnic disparities in youths' exposure to violence. American Journal of Public Health, 103(3), 435-442. doi:10.2105/AJPH.2012.300931 